\title{
Context effects on retrieval at ages 3 and 4
}

\author{
NANCY ANGRIST MYERS and JAMES G. THOMPSON \\ University of Massachusetts, Amherst, Massachusetts
}

\begin{abstract}
Children aged 3 and 4 were asked to name from memory items belonging in a house. Experimental groups completed the task twice, under two conditions. In the function-context condition, the experimenter provided a verbal description of use in response to each item named. In the objectcontext condition, the child was given a miniature replica of each item named. A control group at each age received only general encouragement for each response. Results indicated that the function context was more facilitative to retrieval than was the object context, which did not differ in effect from the control condition. Function context also had major effects on the types of items retrieved: More room items and fewer people and animals were produced in the functioncontext condition than in the other conditions. The representation of function and action in early conceptual schemes is discussed.
\end{abstract}

Considerable work from a number of different perspectives in developmental cognition has been directed toward increased understanding of knowledge structures of the young child. The research has yielded surprisingly consistent general descriptions of young children's retrieval from long-term memory. Response protocols are depicted as sparse, abbreviated, incomplete. It is apparent that young children find it very difficult to address specific memory areas and obtain appropriate information upon demand.

What is less apparent is which environmental support or cuing procedures are most helpful to memory search at very young ages. It has been suggested that the younger the child, the more dependent he/she may be on external support, concrete, realistic object cues, reinstated real-life context, schematic organizations, and so forth for access to his/her memory system (e.g., Brown, 1982; Mandler, 1979). Several studies have supported these hypotheses with respect to memory for specific experimental episodes (e.g., Hudson \& Fivush, 1983; Myers \& Perlmutter, 1978). As far as we know, however, only one previous experiment systematically examined longterm memory retrieval as a function of external context manipulation.

In that study, Ratner and Myers (1981) explored the domain of knowledge about object locations in the home. Using a verification task, they demonstrated that even 2year-old children have quite extensive knowledge of this sort, and that this knowledge base appears to be quite similar from ages 2-5. When retrieval was demanded in a production task, however, children produced far less than they appeared to know. Even when two room objects were introduced as external context cues in a second experi-

This research was supported by NSF Grant No. 7822970. We thank Hilary Horn Ratner for significant contributions to early planning of this work, and Janice Harper and Charlotte Hebert for help in data collection. Reprint requests should be sent to: N. A. Myers, Department of Psychology, University of Massachusetts, Amherst, MA 01003. ment, memory was not facilitated. Yet the external cues did influence the type of information retrieved, and limited inappropriate responding.

Ratner and Myers (1981) examined production for two specific rooms in a house as a function of object context. Some 3- and 4-year-olds were given exactly two objects, either high or low associates of the rooms, before being asked to name items found there. Other children at each age level were not given any room objects. As we have said, these object-context cues did not improve production. It is possible that object cues are not effective in helping young children enter memory and retrieve related objects. Alternatively, object cues may be helpful, but more external object support than was provided in the first experiment is required for 3- and 4-year-olds to gain access to information in long-term memory.

The results of another experiment in this domain are presented here. We evaluated the effects of type of context in a production task in which children were asked to name items found in a house. In one condition in the present study, a miniature replica of the object named (object context) was provided for each item the child produced, and children thus received many more than two objects to support retrieval. Production with this object context was compared to that in a condition in which verbal descriptions of use (function context) were provided for each item produced. A number of studies (e.g., Heidenheimer, 1978; Huttenlocher, Smiley, \& Charney, 1983; Nelson, 1979; and many others) point to the actionoriented, functionally defined nature of very young children's concepts. Function should be strongly represented in early memory, then, and functional-use statements may be the more effective context for search, providing better access to information embedded in memory structures. This may be particularly true for the younger age group, since for the older children, object names may be more closely related to each other than are functions and object names (Huttenlocher \& Lui, 1979). Of course, the type of context may affect the type of information 
retrieved as well as the amount. The major questions to be answered in this experiment, then, were whether object or function context improves or changes retrieval from long-term memory at ages 3 and 4 , and whether these types of context are differentially facilitative as a function of age.

\section{METHOD}

\section{Subjects}

Eighteen boys and 18 girls in each of two age groups, averaging 3 years 6 months, and 4 years 6 months, participated in this study. All children were from middle-class homes in the greater Springfield, Massachusetts area. Parents brought their children to the University of Massachusetts Child Study Center and received a small sum for their participation.

\section{Design}

Six boys and 6 girls at each age level were assigned to each of two experimental groups and to the no-context control group. Subjects were randomly assigned to four experimenters, each of whom conducted six sessions in each of the conditions.

\section{Apparatus}

A large, unfinished six-room plywood dollhouse was placed on a low table in a small experimental room. A timer and a cassette tape recorder were placed on an adjoining table. On the opposite wall, a bookshelf containing an extensive supply of miniature replicas of household-related items was positioned in such a way as to conceal the items from the subject. A small cart with furniture, identified as a moving van, was also used for warm-up activity.

\section{Procedure}

After the children were acclimated to the laboratory setting, they and their parents were invited to play the game in the nearby room already described. The parent sat in a chair next to the dollhouse and the child sat or stood in front of the dollhouse, with the experimenter to one side. Children were asked to pretend they were moving into this new house, were told they could identify the rooms in whatever manner they liked, and were encouraged to play with the moving van

Experimental groups. The experimenter then set the timer for a 5min period (Trial 1). In both context conditions, children were asked to suggest objects needed to furnish the house, and were given a variety of generalized responses indicating approval and encouraging further production for the full $5 \mathrm{~min}$ until the timer chimed. The experimenter then indicated that one way to play the game was completed, and reset the timer for another 5-min period (Trial 2) while introducing the second context procedure. The context orders were counterbalanced, with half the subjects receiving the function context first, and the remaining subjects the object context first.

Function-context condition. In this context condition, each response the child gave was followed not only by generalized approval but also by the experimenter describing how that item might be used. An appropriate function was attributed to each object. For example, if the child suggested that a stove was needed for the house, the experimenter would reply, "Good idea, we could use the stove to cook with; what else does the house need?"

Object-context condition. In this context condition, each response was followed once again with general approbation and further query, but the experimenter also provided for the child a miniature replica of the object named, to place in the dollhouse. If the child suggested "stove," the experimenter would reply, "Good idea, here's a stove for the house; what else does the house need?" When the object-context condition was first, the experimenter enlisted the child's help in removing all objects, and they were concealed before the second procedure was instituted.

No-context control group. Children in the control group received a single 5-min production task in which only generalized statements of approval and a variety of queries for further items were delivered by the experimenter. They were given neither the functional-use statements nor the miniature replica items in response to their production.
Table 1

Mean Number of Production Responses as a Function of Condition and Age

\begin{tabular}{ccccc}
\hline & $\begin{array}{c}\text { Function } \\
\text { Context }\end{array}$ & $\begin{array}{c}\text { Object } \\
\text { Context }\end{array}$ & $\begin{array}{c}\text { No } \\
\text { Context }\end{array}$ & $\begin{array}{c}\text { Averaged Over } \\
\text { Conditions }\end{array}$ \\
\hline Age 3 & 13.42 & 10.58 & 8.67 & 10.89 \\
Age 4 & 16.58 & 10.33 & 13.67 & 13.53 \\
Averaged Over Ages & 15.00 & 10.46 & 11.17 & \\
\hline
\end{tabular}

\section{RESULTS}

\section{Total Production}

The mean number of responses produced by children in three conditions are presented in Table 1 . The responses in the function- and object-context conditions represent those of 3- and 4-year-olds in the experimental groups in the initial context presented to them, and are compared to the responses of the no-context control group. In a 2 (age) $\times 2$ (sex) $\times 3$ (condition) analysis of variance on these responses, this condition effect was found to be significant $[F(2,66)=4.14, p<.05]$. Pairwise comparisons using the Newman-Keuls procedure showed that production in the function context differed significantly from that in the object context. While overall the number of items produced increased with age $[F(1,66)=6.45$, $p<.05]$, the interaction between age and condition was marginally significant $[F(2,66)=2.59, p<.08]$, and $t$ tests carried out separately for each condition showed a significant difference in performance with age only in the no-context condition $[t(22)=3.27, p<.01]$.

The between-groups analysis suggested, then, that the function context was more facilitative to production than was the object context. Analysis of the within-subject manipulation of context provided corroboration. The mean number of responses produced by experimental subjects in the function context was 14.06, whereas the mean number of their responses in the object context was 10.04 . A 2 (age) $\times 2$ (order of context conditions) $\times 2$ (sex) $\times 2$ (context) analysis of variance showed this context effect to be highly significant $[F(1,40)=27.17$, $p<.001]$. Overall production of the two age groups did not differ significantly, averaging about 12 responses per trial. Girls produced an average of 13.39 items per trial, while boys produced 10.70 items. This sex effect was significant $[F(1,40)=5.94, p<.05]$. Production on the first and second trials did not differ significantly, and no other significant effects involving trials were noted. Finally, numbers of repetitions in production were analyzed, but these were few, and did not vary systematically with condition, age, or sex.

\section{Types of Production}

To examine more carefully the production of children at both ages in the two experimental conditions, responses were categorized into the three types summarized below, which accounted for $95 \%$ of 3 -year-olds' and $98 \%$ of 4 year-olds' responses. The remaining responses were categorized as inappropriate or unclassifiable. Separate 
analyses of each response type were carried out on both the numbers and the percentages of total production which were of this type.

Room-specific items were defined as items which were room-defining and included a number of appropriate furniture, appliance, and fixture responses. Room-specific items comprised $50 \%$ of the production of 4-year-olds, whereas among 3-year-olds the average was $38 \%[F(1,40)$ $=6.58, p<.05]$. Four-year-olds also produced significantly more room-specific items than did 3-year-olds-a mean of 6.06 items for the former compared to 4.18 for the latter $[F(1,40)=9.37, p<.01]$. The number of room-specific items produced was also influenced by the context condition. The mean number of responses in the function context was 5.7, and the mean number of responses in the object context was $4.5[F(1,40)=7.18$, $p<.05]$. The room-specific production was further examined for the number of different rooms represented, and for evidence of clustering by room. An average of 3.2 rooms were represented, but very few room clusters were observed, and no significant effects of age or context condition were noted.

Nonspecific room items were defined as items which were not associated with any particular room, such as rugs, curtains, and lights. Nonspecific room items of this type comprised $43 \%$ of the 3-year-old protocols, and $37 \%$ of 4-year-old production; the age effect was not significant. Significant context effects were obtained, however, on both percentage and number of nonspecific room items. The mean proportions of responses of this type were $47 \%$ in the function context, and $33 \%$ in the object context $[F(1,40)=19.13, p<.001]$. The mean number of nonspecific room items produced in the function-context condition was 7.0, while in the object-context condition the mean was $3.5[F(1,40)=36.54, p<.001]$,

The third major response type consisted of people and/or animal responses. In this instance, object context resulted in more people or animal responses. The mean percentage of total responses which were animals or people in the object-context condition was $18 \%[F(1,40)=$ $22.5, p<.001]$. The mean number of people/animal responses in the function-context condition was 1.25 , while the mean in the object-context condition was 2.08 $[F(1,40)=9.46, p<.01]$. Girls produced more responses of this type than did boys-a mean of 2.35 versus a mean of 0.98 items, respectively $[F(1,40)=$ $9.24, p<.01]$. Animals and people comprised $17.8 \%$ of total production of girls, and $7.3 \%$ of total production of boys $[F(1,40)=9.95, p<.01]$.

\section{DISCUSSION}

Functional-use statements were clearly useful to the children in this study as they sought to retrieve information about objects found in the home. At both ages, significantly more items were retrieved in the function-context condition than in the object-context condition, and types of response were also affected. Given functional-use statements for the items they suggested, children reported more furniture and appliances defining specific rooms, more nonspecific room items, and fewer people and animals than when they were given miniature replicas of the objects they named. These findings strongly support descriptions of young children's knowledge organizations which emphasize their action base. They also permit us to appreciate further the power of function or action in early memory. We can conceive of each functional-use statement as providing an entry to the child's memory representation from which he/she can trace out a route to further information. That is, not only may early concepts be functional in nature, but access to information in them appears to be better afforded through functional-action routes.

In sharp contrast to the facilitating effects of functional context, providing external object context in the form of miniature replicas of items named did not increase production over that in the no-context control condition. Furthermore, fewer specific and nonspecific room objects, and more people and animals were recalled. Thus, even when many more than the two objects presented in Ratner and Myer's (1981) study were available, object context did not improve retrieval. With children as young as 3 years, concrete, realistic objects were less effective cues than nonconcrete, nonexternal verbal statements about actions performed with the objects. Of course, a considerable amount of concrete, external support was present for all children in the form of the dollhouse. Nonetheless, additional functional context was clearly more helpful than additional object context, even for the youngest children.

In general, age-based differences were not large, and context affected the performance of children of both ages similarly. The quantity of production was no different for 3- and 4-year-olds in either context condition. Only in the no-context control condition did the older children retrieve more items than the younger children. Qualitatively, the 4-yearolds recalled more room-specific furniture and appliances than did the 3 -year-olds.

Three major methodological changes from the original study (Ratner \& Myers, 1981) were introduced in this study. The task was presented as a moving-into-a-new-house game; a moving van and furniture were provided as warm-up materials; and the entire house, rather than two individual rooms, was defined as the production domain. These procedural differences make direct comparisons with results of the earlier study problematic. It is true, for example, that almost all children produced items for three different rooms, and many for four rooms, and virtually no room clustering was observed. It is interesting, however, that production in all three conditions in this experiment was considerably elevated when compared to that of the earlier study. This was particularly noticeable in the function-context condition: 3-year-olds in the single function-context trial, for instance, produced twice as many items as those in the first study did for two trials combined. We believe that both staging the task as a moving-day event and providing actions in the function-context condition were important to accessing knowledge, especially for the younger children. This is consistent with the positions of Mandler $(1979,1983)$ and Nelson and Gruendel $(1981)$, emphasizing young children's heavy reliance on scene and event schemas.

Moreover, greater retrieval was obtained with no sacrifice in quality. At both ages, there was little truly inappropriate responding. People and animal responses may have reflected some slight reliance on personal autobiogaphical information, as in the previous study. Most importantly, over $80 \%$ of items retrieved were specific or nonspecific room objects, for both age groups. Thus, as demonstrated previously, the children were able to address this well-established knowledge base in appropriate fashion and provide relevant information upon demand.

The facilitation afforded by the functional-use statements was obvious, however, and the answers to our initial questions are evident. Object context is not helpful to either 3- or 4-year-olds in this production task. Function context changes and improves retrieval from long-term memory at both ages. These findings permit us to both underline and expand current statements about early memory. In a general sense, Nelson's (1979) theory emphasizing the central role of function in early knowledge representation clearly gains support. A specific extension of this model now seems merited. Not only do early concepts appear to be organized around a function core, but functional-use statements are seen to afford better access to information embedded in these memory structures. 


\section{REFERENCES}

Brown, A. L. (1982). Learning and development: The problems of compatibility, access, and induction. Human Development, 25, 89-115. HeIDENheimER, P. A. (1978). A comparison of the roles of exemplar, action, coordinate, and superordinate relations in the semantic processing of 4- and 5-year-old children. Journal of Experimental Child Psychology, 25, 143-159.

Hudson, J., \& Fivush, R. (1983). Categorical and schematic knowledge and the development of retrieval strategies. Journal of Experimental Child Psychology, 36, 32-42.

HUTTENLOCHER, J., \& LUI, F. (1979). The semantic organization of some simple nouns and verbs. Journal of Verbal Learning \& Verbal Behavior, 18, 141-162.

Huttenlocher, J., Smiley, P., \& Charney, R. (1983). Emergence of action categories in the child: Evidence from verb meanings. Psychological Review, 90, 72-93.

MANDleR, J. M. (1979). Categorical and schematic organization in memory. In C. R. Puff (Ed.), Memory organization and structure. New York: Academic Press.
Mandler, J. M. (1983). Representation. In J. H. Flavell \& E. M. Markman (Eds.), Cognitive development, Vol. 2 of P. Mussen (Ed.), Manual of child psychology. New York: Wiley.

Myers, N., \& Perlmutter, M. (1978). Memory in the years from two to five. In P. A. Ornstein (Ed.), Memory development in children. Hillsdale, NJ: Erlbaum.

Nelson, K. (1979). Explorations in the development of a functional semantic system. In W. A. Collins (Ed.), 12th Minnesota Symposium on child Psychology. Hillsdale, NJ: Erlbaum.

Nelson, K., \& Gruendel, J. (1981). Generalized event representations: Basic building blocks of cognitive development. In M. Lamb \& A. Brown (Eds.), Advances in developmental psychology (pp. 131158). Hillsdale, NJ: Erlbaum.

RATNER, H. H., \& MYERS, N. A. (1981). Long-term memory and retrieval at ages 2, 3, 4. Journal of Experimental Child Psychology, 31, 365-386.

(Manuscript received for publication June 27, 1985.) 